\title{
Removing and Recovering Phosphate from Poultry Wastewater Using Amorphous Ceramics
}

\author{
Youhui Xie, Qin Li, Xianzhi Zhao, Yi Luo, Yangming Wang, Xiangwei Peng, \\ Qigui Wang, Jian Su, and Yin Lu
}

\author{
Chongqing Academy of Animal Science, Chongqing 402460, China \\ Correspondence should be addressed to Yangming Wang; cqwym@126.com
}

Received 20 February 2014; Revised 22 April 2014; Accepted 22 April 2014; Published 21 May 2014

Academic Editor: Fan Dong

Copyright (c) 2014 Youhui Xie et al. This is an open access article distributed under the Creative Commons Attribution License, which permits unrestricted use, distribution, and reproduction in any medium, provided the original work is properly cited.

\begin{abstract}
A novel and effective technique for phosphate from poultry wastewater was developed using amorphous ceramics. Amorphous ceramics, which showed high performance for phosphate removal and recovery from poultry wastewater, were synthesized using unlimitedly available, inexpensive materials such as silica fume and lime. Dissolved phosphate in poultry wastewater can be deposited as a solid on the surface of amorphous ceramics. Phosphate content on the surface of amorphous ceramics could reach $14.20 \%$. The phosphate removal and recovery process and mechanism was revealed by a series of characterizations, such as XRD, FESEM, BET, and so on. The present study demonstrated that amorphous ceramics have great potential as a novel, beneficial material for removing and recovering phosphate from poultry wastewater.
\end{abstract}

\section{Introduction}

The pollution caused by livestock and poultry breeding is not only a local environmental problem, but also a big basin environmental issue $[1,2]$. Especially, high concentration of phosphate discharged from poultry wastewater was one of the main incentives of eutrophication $[3,4]$. Therefore, removing phosphate from poultry wastewater has been the present research hotspot [5-7].

According to the supersaturation theory, when the concentration of $\mathrm{Ca}^{2+}, \mathrm{OH}^{-}$, and phosphate ion reaches saturation state, phosphate can be deposited in the form of calcium orthophosphate on the surface of crystal seed $[8,9]$. Previous studies showed that calcium silicate hydrate can be used as the crystal seed [10-13]. And the phosphate recovery efficiency of calcium silicate hydrate was about $13 \%$ according to the existing research $[14,15]$. The crystallization process could remove phosphate in wastewater by producing calcium orthophosphate on the surface of granular seed crystal [1618]. This process possesses the advantages of easy dewatering and potential phosphate recycling for the product. Due to the unique chemical composition of amorphous ceramics, it could ensure the efficient removal and the recovery of soluble phosphate [19]. From a theoretical and practical point of view, micromorphology of amorphous ceramics was also important for increasing reaction rate of phosphate recovery [20]. This critical issue has not yet been sufficiently solved so far. Overall, the goal of this study was to define the micromorphology properties and to optimize the influence conditions for amorphous ceramics to remove and recover phosphate.

Laboratory experiments were carried out to investigate the key features of the removing and recovering process. Theoretical analysis and experimental evidences were also provided to demonstrate the underlying principles of crystallization and mechanism of the process. The originality and importance that can be drawn from this study are summarized, such as examining the effects of $\mathrm{pH}$ value, stirring intensity and dosage of amorphous ceramics on the phosphate removal and recovery efficiency. Then, cycling phosphate removal experiments were performed to evaluate the phosphate recovery performance of amorphous ceramics. The applicability of the phosphate recovery system using amorphous ceramics as a seed crystal was also examined. At last, by using Avrami kinetics equation, the capacity of $\mathrm{Ca}^{2+}$ release and the pore structure of amorphous ceramics 
TABLE 1: Chemical components of silica fume and lime.

\begin{tabular}{lccccccccc}
\hline & \multicolumn{1}{c}{ Chemical components (contents) $\%$} \\
& $\mathrm{CaO}$ & $\mathrm{SiO}_{2}$ & $\mathrm{Al}_{2} \mathrm{O}_{3}$ & $\mathrm{SO}_{2}$ & $\mathrm{MgO}$ & $\mathrm{Fe}_{2} \mathrm{O}_{3}$ & $\mathrm{NaOH}$ & $\mathrm{CuO}$ & $\mathrm{H}_{2} \mathrm{O}$ \\
\hline Lime & 79.60 & 3.35 & 2.36 & 1.18 & 0.66 & 0.17 & - & - \\
Silica fume & 0.04 & 97.50 & 0.15 & 1.83 & - & 0.02 & 0.30 & 0.01 & 0.15 \\
\hline
\end{tabular}

were determined. The mechanism of phosphate recovery by amorphous ceramics as seed crystal on the condition of weak alkaline was also revealed.

\section{Materials and Methods}

2.1. Materials. Amorphous ceramics were synthesized using silica fume as the silicon oxide materials and lime as calcium oxide materials, respectively. Lime (calcareous, hoar and powdery, Chongqing Changshou Chemical Co., Ltd.) was calcined at $700^{\circ} \mathrm{C}$ for $2 \mathrm{~h}$. The chemical constituents of silica fume (Particles present spherical with homogeneous diameter, Chongqing Jianfeng chemical Co., Ltd.) and lime are in Table 1 . The phosphate solution was poultry wastewater. The phosphate concentration of poultry wastewater was $40 \mathrm{mg} / \mathrm{L}$, and $\mathrm{pH}$ value was 7.0 7.5. The above materials and chemicals were placed into sealed bottles for storage.

2.2. Preparation of Amorphous Ceramics. Amorphous ceramics were prepared with lime (providing $\mathrm{CaO}$ ) and silica fume (providing $\mathrm{SiO}_{2}$ ). Lime and silica fume were mixed with a molar ratio of $1.5 \sim 1.6$. The mixture was then added to prepared slurries. The slurry was hydrothermal reacted at $165 \sim 170^{\circ} \mathrm{C}$ for $6 \mathrm{~h}$ and taken out when the temperature was reduced to the natural conditions. The hydrothermal reaction was carried out with a liquid/solid ratio of $29 \sim 30$. The obtained products were dried at $105^{\circ} \mathrm{C}$ for $2 \mathrm{~h}$ and then were ground through a sieve of 200 meshes.

\subsection{Phosphate Removal and Recovery Using Amorphous} Ceramics. The $\mathrm{pH}$ values of phosphate-content solution were in the range of 7.0-7.5 before the amorphous ceramics samples were added to this solution. The experiment temperature condition is $20^{\circ} \mathrm{C}$. Continuous phosphate removal tests were carried out using amorphous ceramics for the removal of phosphate from poultry wastewater. Amorphous ceramics samples (dosage of samples $0.5,1.0,2.0,3.0$, and $4.0 \mathrm{~g} / \mathrm{L}$, resp.) were added to a series of bottles and stirring (40, 60 80,100 , and $120 \mathrm{r} / \mathrm{min}$, resp.) under controlled temperature conditions $\left(20^{\circ} \mathrm{C}\right)$. Phosphate concentration of supernatant was measured according to the molybdenum blue ascorbic acid method (the relative error of data is $0.3 \%$ ) with a spectrophotometer (UV-2012PCS, Shanghai Unico Instruments Co., Ltd., China). The solid samples were then separated from the removed synthetic solution with the addition of samples after reaction. Finally, the produced sediments were separated from removed synthetic solution, dried, and weighted. Phosphate is contented by (1), where $C_{t}$ is the restrained phosphate concentration in synthetic solution $(\mathrm{mg} / \mathrm{L}), v$ is the volume of the solution $(L), w$ is the mass of produced sediment after phosphate recovery $(\mathrm{mg})$, and $C_{0}$ is the initial phosphate concentration $(\mathrm{mg} / \mathrm{L})$ :

$$
P=\frac{\left(c_{0}-c_{t}\right) \times v}{w} \times 100 \% .
$$

2.4. $\mathrm{Ca}^{2+}$ Release Experimental of Amorphous Ceramics. $1 \mathrm{~g}$ of amorphous ceramics samples was immersed in $1 \mathrm{~L}$ of demonized water contained in a glass bottle, generating samples with a solution concentration of $1 \mathrm{~g} / \mathrm{L}$. The bottle was placed on an agitation table and shaken at $40 \mathrm{r} / \mathrm{min}$ under controlled temperature conditions $\left(20^{\circ} \mathrm{C}\right)$. Samples of solution were taken after $5,10,15,20,40$, and $60 \mathrm{~min}$ of agitation. $\mathrm{Ca}^{2+}$ concentration of samples was determined by EDTA titration (the relative error of data is $0.05 \%$ ).

2.5. Characterization Methods. X-ray diffraction (XRD) patterns were collected in an XD-2 instrument (Persee, China) using $\mathrm{Cu} \mathrm{K} \alpha$ radiation.

Field emission scanning electron microscopy (FESEM) images were collected on an S-4800 field emission scanning electron microscope (Hitachi, Japan).

Brunauer-Emmett-Teller (BET) surface areas were measured by nitrogen adsorption at $77.35 \mathrm{~K}$ on an ASAP-2010 adsorption apparatus (Micromeritics, USA).

\section{Results and Discussion}

3.1. Phase Structure of Amorphous Ceramics. The XRD patterns of amorphous ceramics before phosphate removal, phosphate removal for the first time, and phosphate removal for 6 times were compared (Figure 1). The main phase of amorphous ceramics was Jennite (PDF card 18-1206, chemical formula $\left.\mathrm{Ca}_{9} \mathrm{Si}_{6} \mathrm{O}_{18}(\mathrm{OH})_{6} \cdot 8 \mathrm{H}_{2} \mathrm{O}\right)$. After phosphate removal for the first time, the dominant peaks of Jennite were obviously weakened, and the weak peaks of calcium orthophosphate (PDF card 09-0432, chemical formula $\left.\mathrm{Ca}_{5}\left(\mathrm{PO}_{4}\right)_{3}(\mathrm{OH})\right)$ emerged at $25.88^{\circ}, 31.76^{\circ}$, and $53.26^{\circ}$. The sharp dominant peaks of calcium orthophosphate appeared after phosphate removal for 6 times instead of the dominant peaks of Jennite. This phenomenon indicated that original property of amorphous ceramics seed crystal disappeared and transformed to calcium orthophosphate during the phosphate recovery process.

3.2. BET Surface Areas and Pore Structure of Amorphous Ceramics. Nitrogen adsorption-desorption isotherms of amorphous ceramics before and after phosphate removal are shown in Figure 2. The specific surface areas of these 


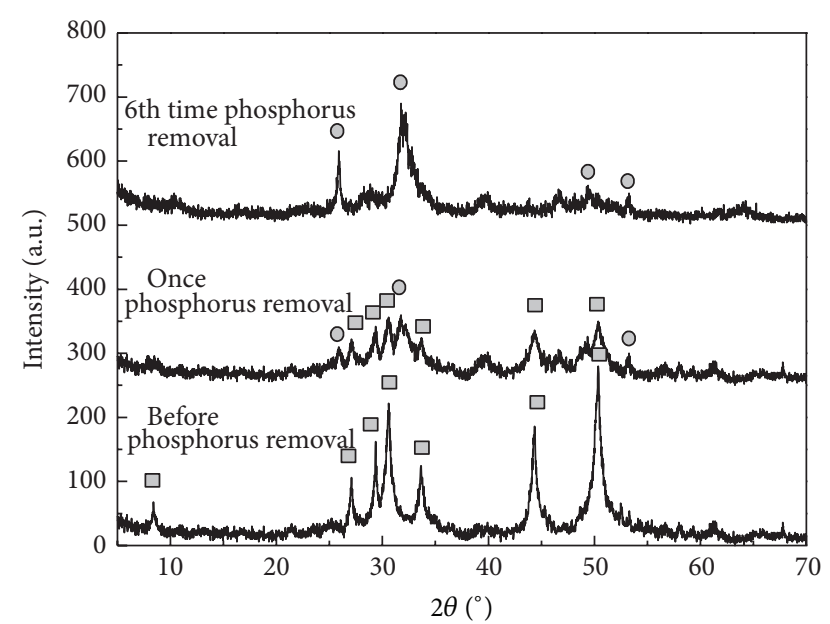

$\square$ Jennite

○ Calcium orthophosphate

FIGURE 1: XRD patterns of samples.

samples were $114.14,57.38,34.25,23.74$, and $7.55 \mathrm{~m}^{2} / \mathrm{g}$, respectively. Pore volumes of these samples were $0.52,0.31,0.12$, 0.09 , and $0.04 \mathrm{~cm}^{3} / \mathrm{g}$, respectively. These results indicated that the specific surface areas and pore volumes decreased with the increase of phosphate removal times. Figure 2 shows the phenomenon of adsorption hysteresis loop. This implies that mesopore or narrow gap pore exists in the samples. Adsorption in mesopore occurred mainly in medium pressure region $\left(0.4<P / P_{0}<0.9\right)[21,22]$. The phenomenon of adsorption hysteresis loop disappeared gradually with the increased phosphate removal times. The FESEM photographs of amorphous ceramics before and after removing phosphate are shown in Figure 3. Before phosphate removal, amorphous ceramics possess obvious porous structure with a large number of mesopores (Figure 3(a)). The micrograph in Figure 3(b) reveals that amorphous ceramics are covered with finely distributed crystalline substances, which was calcium orthophosphate as indicated in XRD result.

3.3. Kinetic of $\mathrm{Ca}^{2+}$ Release. The effect of phosphate removal for the first 4 times on the $\mathrm{Ca}^{2+}$ release capacity of amorphous ceramics was investigated (Figure 4 ). $\mathrm{Ca}^{2+}$ concentration released from amorphous ceramics decreased with the increase of phosphate removal times. The maximum $\mathrm{Ca}^{2+}$ concentration released from amorphous ceramics was $3.02 \mathrm{mg} / \mathrm{g}$ before phosphate removal. This concentration decreased to $1 \mathrm{mg} / \mathrm{g}$ after phosphate removal for 4 times. Avrami kinetic equation could describe how the solid change from one phase state to another (that means phase transition), which could also describe the chemical reaction rate [23]. So, the experimental capacities of $\mathrm{Ca}^{2+}$ release could be fitted by Avrami kinetic equation; the model is as follows:

$$
-\ln (1-x)=k t^{n}
$$

where $k$ is the kinetic constant, $n$ is the characteristic constant of solid, $t$ is the reaction time (min), and $x\left(x=C_{t} / C_{\max }, C_{t}\right.$ is concentration of time $t(\mathrm{mg} / \mathrm{L})$, and $C_{\max }$ is concentration

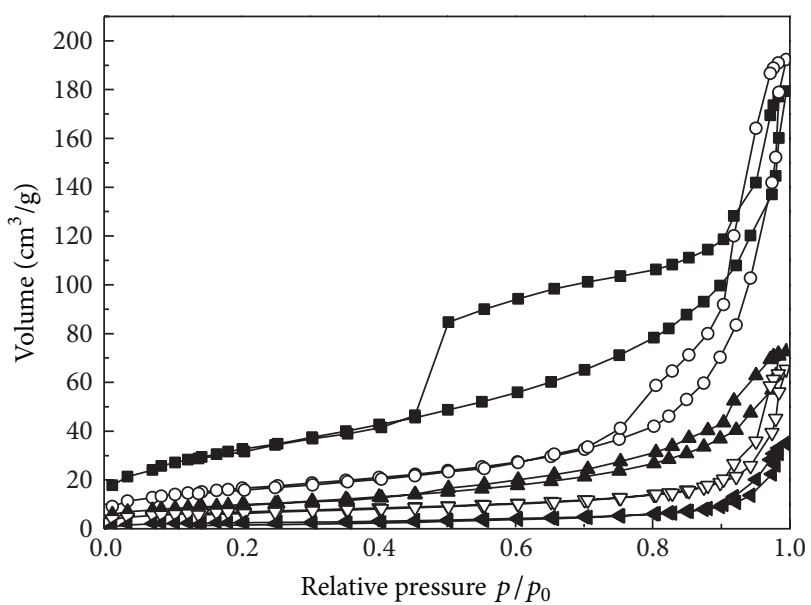

$$
\begin{aligned}
& - \text { Before phosphorus removal } \rightarrow \text { 3rd time phosphorus removal } \\
& \multimap-\text { Once phosphorus removal } \longleftarrow \text { th time phosphorus removal } \\
& \neg \text { Twice phosphorus removal }
\end{aligned}
$$

FIGURE 2: Nitrogen adsorption-desorption isotherms of amorphous ceramics before and after removing phosphate.

TABLE 2: The correlate constants for the Avrami kinetic equation describing $\mathrm{Ca}^{2+}$ release.

\begin{tabular}{lccc}
\hline Samples & $n$ & $k$ & $R^{2}$ \\
\hline Before phosphate removal & 0.9156 & 0.0758 & 0.9893 \\
Once phosphate removal & 0.9204 & 0.0682 & 0.9752 \\
Twice phosphate removal & 0.9182 & 0.0602 & 0.9790 \\
3rd time phosphate removal & 0.8687 & 0.0564 & 0.9548 \\
4th time phosphate removal & 0.9913 & 0.0301 & 0.9836 \\
\hline
\end{tabular}

of the maximum $(\mathrm{mg} / \mathrm{L}))$ is the fraction conversion. The characteristic constant $n$ was 0.9156 . The kinetic constants were determined by fitting the Avrami kinetic equation to the experimental data obtained (Table 2 ).

The high correlation coefficients $\left(R^{2}>0.9\right)$ indicated that this model could well describe the law of $\mathrm{Ca}^{2+}$ release. Combined with specific surface area $(S)$ of samples, a relationship between $k$ and $S$ could be established:

$$
k=0.1502 S^{0.3695} \quad R^{2}=0.9232 .
$$

According to (3), the larger surface area of amorphous ceramics could result in faster $\mathrm{Ca}^{2+}$ release. Subsequently, the concentration of $\mathrm{Ca}^{2+}$ release increased.

\subsection{Phosphate Removal with Amorphous Ceramics}

3.4.1. Effect of $p H$ Values. The effect of $\mathrm{pH}$ values on the phosphate ions removal performance was investigated with the initial phosphate concentration $40 \mathrm{mg} / \mathrm{L}$ (Figure 5). The results in Figure 5 show that $\mathrm{pH}$ value has an obvious effect on the residual phosphate concentration. The residual phosphate concentration was up to $7.7 \sim 9.1 \mathrm{mg} / \mathrm{L}$ when the $\mathrm{pH}$ values were in the range of $4.0 \sim 7.0$. In this range of $\mathrm{pH}$ values, the solution has not reached supersaturation with $\mathrm{Ca}^{2+}, \mathrm{OH}^{-}$, and phosphate ions coexisted. Under this condition, amorphous ceramics did not possess phosphate 


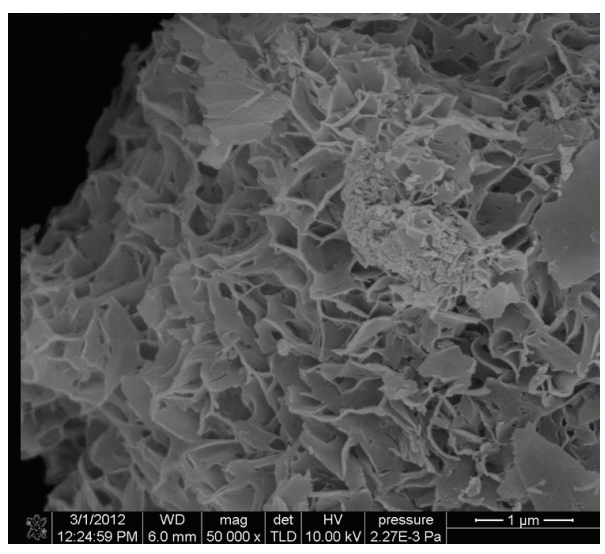

(a)

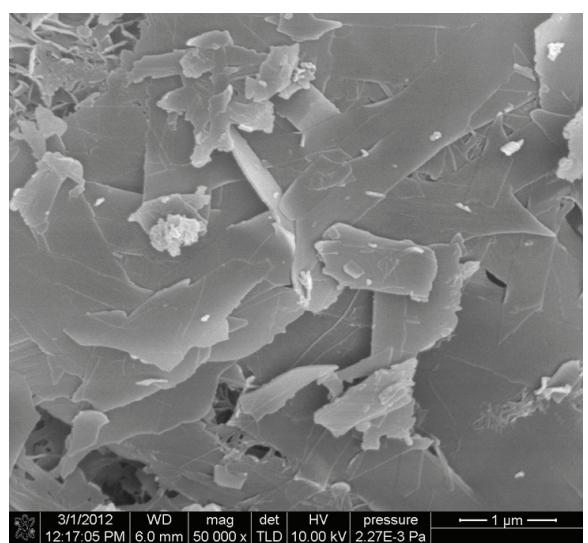

(b)

FIGURE 3: FESEM photographs of amorphous ceramics before and at the 6th time phosphate removal. (a) Amorphous ceramics before phosphate removal. (b) Amorphous ceramics of the 6th time phosphate removal.

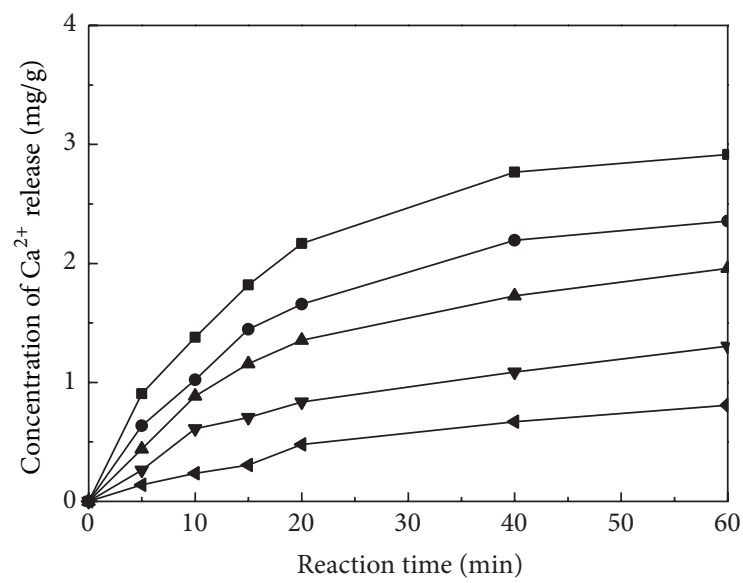

$\rightarrow-$ Before phosphorus removal

- Once phosphorus removal

^- Twice phosphorus removal

FIGURE 4: Concentration of $\mathrm{Ca}^{2+}$ released from samples.

removal performance. At the $\mathrm{pH}$ value of 8.0 , the residual phosphate concentration declined to $4.34 \mathrm{mg} / \mathrm{L}$. When the $\mathrm{pH}$ value reached to 9.0, the phosphate removal performance of amorphous ceramics increased obviously, and the residual phosphate concentration declined to the minimum of $0.82 \mathrm{mg} / \mathrm{L}$. Phosphate existed in the form of $\mathrm{HPO}_{4}{ }^{2-}$ in the range of 8.0 9.0 [24]. The residual phosphate concentration increased with the $\mathrm{pH}$ values increasing continuously. So, the kinetic models of phosphate removal were established at $\mathrm{pH}$ value of 9.0. This reaction is accorded with the tendency of second order reaction kinetics, and the kinetic equation could be established:

$$
\frac{d C}{d t}=-k C^{2}
$$

or

$$
\frac{1}{C_{t}}-\frac{1}{C_{0}}=k t \text {, }
$$

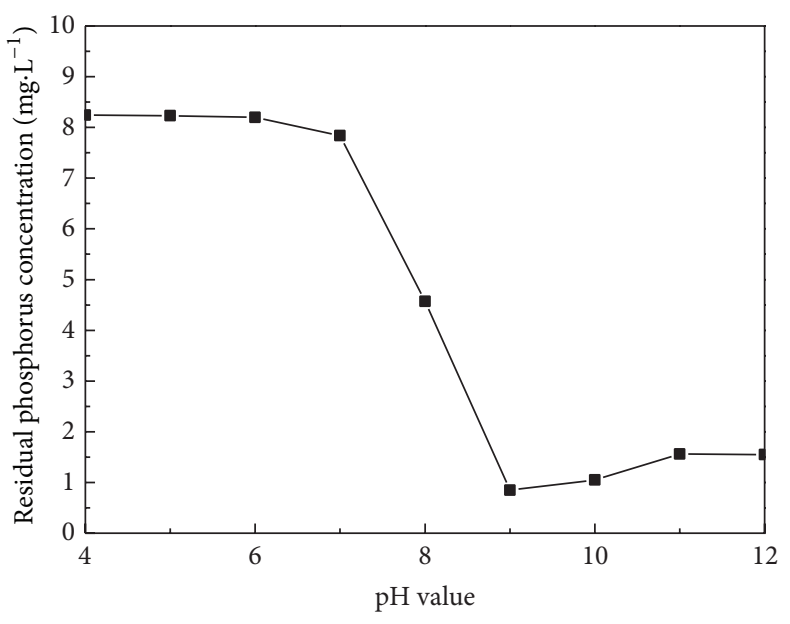

FIGURE 5: Influence of $\mathrm{pH}$ value on residual phosphate concentration.

where $C_{t}$ is the concentration of time $t(\mathrm{mg} / \mathrm{L}), C_{0}$ is the initial time, and $k$ is the kinetic constant.

3.4.2. Kinetic of Phosphate Removal. With the $\mathrm{pH}$ value unchanged, initial phosphate concentration, stirring intensity, and amorphous ceramics dosage have been predicted as the major factors influencing the phosphate removal rate by calcium orthophosphate crystallization. Hence, the overall rate constant $k$ in (6) is likely to be a function of stirring intensity and amorphous ceramics dosage,

$$
k=f(M, I)=a M^{b} I^{c},
$$

where $b, c$, and $d$ were constants and $M$ and $I$ were amorphous ceramics dosage and stirring intensity, respectively.

The effect of amorphous ceramics dosage on the removal of phosphate was investigated at amorphous ceramics dosages range of $0.5,1,2,3$, and $4 \mathrm{~g} / \mathrm{L}$, respectively (Figure 6). As shown in Figure 6, when the dosages were in the range of $1 \sim 4 \mathrm{~g} / \mathrm{L}$, the residue phosphate concentration kept unchanged with $4 \sim 5 \mathrm{mg} / \mathrm{L}$. The residue phosphate concentration rose to 


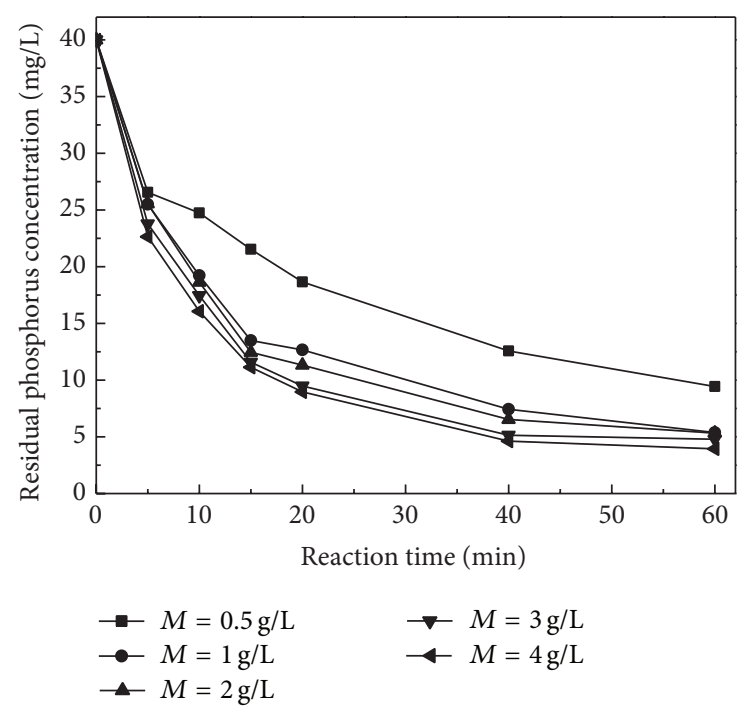

FIGURE 6: Influence of dosage of amorphous ceramics.

$9.45 \mathrm{mg} / \mathrm{L}$ when the dosage was as low as $0.5 \mathrm{~g} / \mathrm{L}$. This result was inconsistent with the conclusion of traditional coagulation precipitation experiment. In the traditional experiment, the removal of phosphate could be better with the increase of dosages of calcium. This is because the removal efficiency of phosphate was much dependent on the alkalinity caused by excess calcium, and the malpractice of this traditional method is reducing the utilization efficiency of calcium. Considering the effective utilization rate from seed, $1 \mathrm{~g} / \mathrm{L}$ is the proper dosages. The reaction rate of phosphate removal increased with the increase of dosage, and the relationship could be fitted as follows:

$$
k=0.0003 M^{1.3865} \quad R^{2}=0.9453 .
$$

Under $\mathrm{pH}$ value of 9.0, amorphous ceramics dosage of $1 \mathrm{~g} / \mathrm{L}$, the results showed that the residual phosphate concentration declined with the increase of stirring intensity when the stirring intensity was lower than $80 \mathrm{r} / \mathrm{min}$. When the stirring intensity reached $80 \mathrm{r} / \mathrm{min}$, the residual phosphate concentration declined to minimum (Figure 7). According to Figure 7, stirring intensity has an obvious influence on the phosphate removal performance of amorphous ceramics. The reaction rate of phosphate removal increased with the increase of stirring intensity. The relationship could be fitted as follows:

$$
k=0.0004 I^{0.4712} \quad R^{2}=0.9247 .
$$

By comprehensive analysis of initial, amorphous ceramics dosage and stirring intensity, (4) could be expressed as follows:

$$
k=a M^{1.3865} I^{0.4712} .
$$

According to (7) and (9), the parameter $a$ can be determined to be 0.0034 . The kinetic model of phosphate removal could be established by taking the coefficient $a$ into (5):

$$
\frac{1}{C_{t}}=\frac{1}{C_{0}}+\left(0.0046 M^{1.3865} I^{0.4712}\right) t
$$

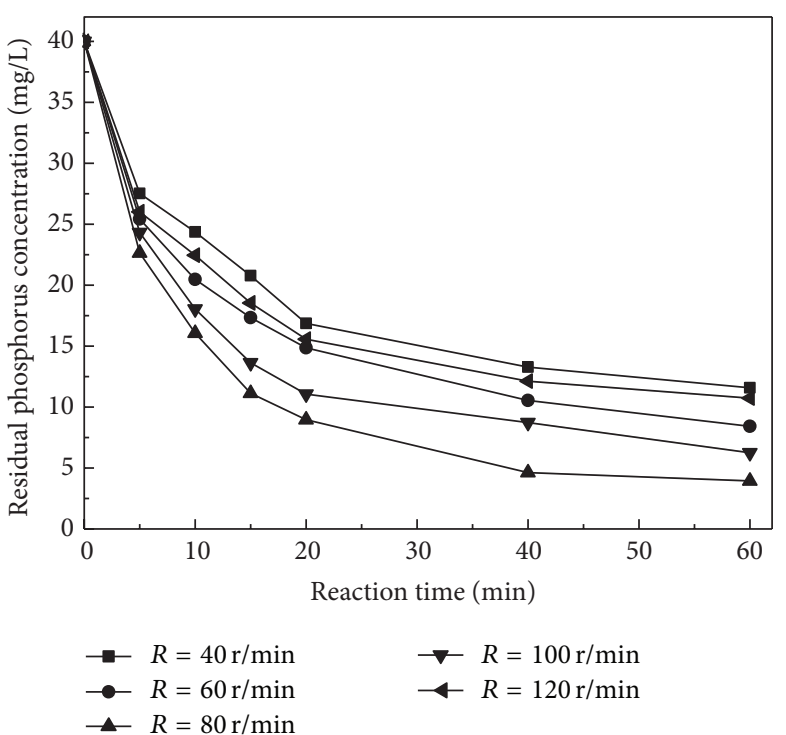

FIGURE 7: Influence of stirring intensity on residual phosphate concentration.

The phosphate recovery process is the calcium orthophosphate crystallization process on the surface of amorphous ceramics. When the stirring intensity is too low, amorphous ceramics cannot touch phosphate wastewater adequately. When the stirring intensity is too high, the calcium orthophosphate crystal cannot be formed due to the strong shearing force.

3.5. The Phosphate Recovery Performance of Amorphous Ceramics. According to (1) and (10), the kinetic model verified the experimental result of phosphate removal. Analysis from the view of phosphate recovery showed that the conditions such as the improvement of initial phosphate concentration, stirring intensity, and the decrease of dosage were beneficial for the improvement of phosphate content of solid segment. But the value of $k$ was only 0.00007 when the amorphous ceramics dosage was $0.5 \mathrm{~g} / \mathrm{L}$. This reaction rate was too low to the engineering application. Thus, the proper dosage should be $1 \mathrm{~g} / \mathrm{L}$, and the reaction rate $k$ was 0.0005 . So, the proper process condition for phosphate recovery using amorphous ceramics is as follows: amorphous ceramics dosage of $1 \mathrm{~g} / \mathrm{L}$ and stirring intensity of $80 \mathrm{r} / \mathrm{min}$. To obtain the maximum efficiency of phosphate recovery continuous experiments were carried out using amorphous ceramics calculated for the removal of phosphate. Changes of residual phosphate concentration by circulation of phosphate removal were shown in Figure 8. For the first 4 times of phosphate removal, the restrained phosphate concentration was changed greatly. The restrained phosphate concentration almost remained stable when phosphate removal circulated for 6 times. The quality of solid segment was $1.08 \mathrm{~g}$ and the phosphate content of solid segment was $14.20 \%$ after the circulation of phosphate removal. The changes of $\mathrm{pH}$ values showed that amorphous ceramics could maintain the $\mathrm{pH}$ value between 8.0 and 9.0 at the first 4 times phosphate removal. Calcium phosphate had been crystallized on the surface of amorphous ceramics 


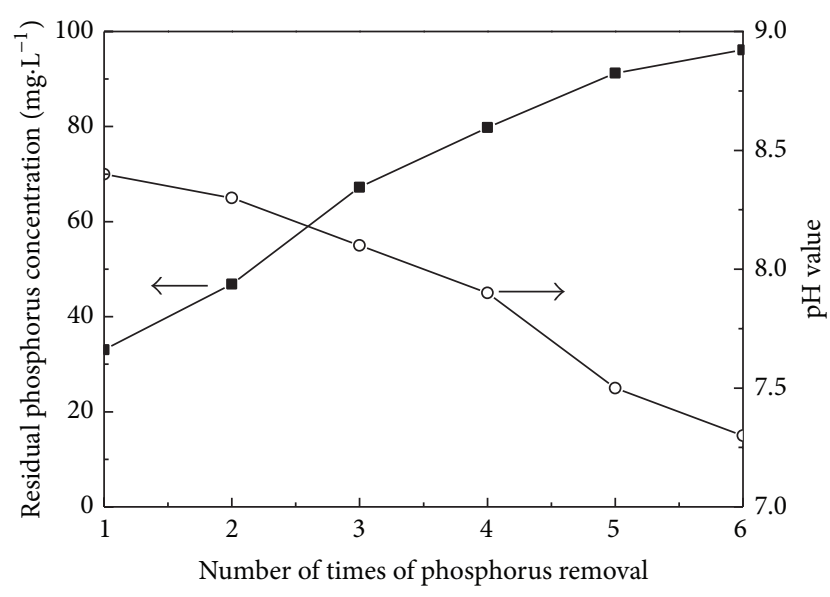

FIGURE 8: Changes of residual phosphate concentration and $\mathrm{pH}$ values.

during the 6 times phosphate recovery process. Thus, BET surface areas and pore volume decreased. Due to the large BET surface areas and pore volume of amorphous ceramics, $\mathrm{Ca}^{2+}$ and $\mathrm{OH}^{-}$can be released continuously, and $\mathrm{pH}$ values increased. During the phosphate recovery process, phosphate sedimentation produced on the surface of amorphous ceramics to block the pore structure to restrain the release of $\mathrm{Ca}^{2+}$ and $\mathrm{OH}^{-}$. The $\mathrm{pH}$ values declined with the increased circulate times of phosphate removal. Subsequently, the phosphate removal performance of amorphous ceramics decreased. The $\mathrm{pH}$ value declined to 7.5 after the circulation of phosphate removal for 6 times. At this time, the restrained phosphate concentration was up to $95.47 \mathrm{mg} / \mathrm{L}$, which indicated that amorphous ceramics did not possess phosphate removal capacity in neutral condition.

Indeed, the phosphate recovery process is the form process of calcium orthophosphate, which is also different from the traditional chemical phosphate removal process. Because the traditional chemical phosphate removal process needs a high alkalinity $(\mathrm{pH}=10.5 \sim 12.5)$ condition to make $\mathrm{Ca}^{2+}, \mathrm{OH}^{-}$, and $\mathrm{PO}_{4}{ }^{3-}$ reach supersaturated, the phosphate sedimentation precipitated would be produced. Under the proper process condition, amorphous ceramics could release a suitable concentration of $\mathrm{Ca}^{2+}$ and $\mathrm{OH}^{-}$to maintain the $\mathrm{pH}$ value during 8.0 9.0. Phosphate existed in the form of $\mathrm{HPO}_{4}{ }^{2-}$ in the range of these $\mathrm{pH}$ values. $\mathrm{Ca}^{2+}, \mathrm{OH}^{-}$, and $\mathrm{HPO}_{4}{ }^{2-}$ formed a local condition with high concentration. This condition was beneficial to the formation of calcium orthophosphate with $\mathrm{pH}=8.0 \sim 9.0$.

\section{Conclusion}

The present work demonstrated that phosphate in poultry wastewater was dropped as the $\mathrm{pH}$ value increased during 8.0 9.0 at a proper $\mathrm{Ca}^{2+}$ and $\mathrm{OH}^{-}$concentration during calcium orthophosphate crystallization. The design factors for calcium orthophosphate crystallization process were investigated systematically using the model proposed in this study. The calcium orthophosphate crystallization was affected by $\mathrm{pH}$ value, stirring intensity, and amorphous ceramics dosage.
The phosphate content of regenerated product obtained by amorphous ceramics reached $14.20 \%$, exceeding that of the regenerated product obtained by tobermorite (13\%) and xonotlite $(10 \%)$. Experiments have also demonstrated the applicability of the phosphate crystallization process as a phosphate recovery system for recycling phosphates in poultry wastewater using amorphous ceramics as seed crystal.

\section{Conflict of Interests}

The authors declare that there is no conflict of interests regarding the publication of this paper.

\section{Acknowledgments}

This work was supported by the National Waterfowl Industry Technology System Chongqing Comprehensive Test Station (CARS-43-43) and one project of Science and Technology Committee in Chongqing named New Variety Breeding of Wulong Black Chicken (CSTC, 2011AC1180, 11301).

\section{References}

[1] L. H. Peng and Y. Bai, "Numerical study of regional environmental carrying capacity for livestock and poultry farming based on planting-breeding balance," Journal of Environmental Science, vol. 25, no. 9, pp. 1882-1889, 2013.

[2] K. Yetilmezsoy and S. Sakar, "Improvement of COD and color removal from UASB treated poultry manure wastewater using Fenton's oxidation," Journal of Hazardous Materials, vol. 151, no. 2-3, pp. 547-558, 2008.

[3] K. Yetilmezsoy, "Integration of kinetic modeling and desirability function approach for multi-objective optimization of UASB reactor treating poultry manure wastewater," Bioresource Technology, vol. 118, pp. 89-101, 2012.

[4] R. Rajakumar, T. Meenambal, P. M. Saravanan, and P. Ananthanarayanan, "Treatment of poultry slaughterhouse wastewater in hybrid upflow anaerobic sludge blanket reactor packed with pleated poly vinyl chloride rings," Bioresource Technology, vol. 103, no. 1, pp. 116-122, 2012.

[5] M. G. Hajaya and S. G. Pavlostathis, "Fate and effect of benzalkonium chlorides in a continuous-flow biological nitrogen removal system treating poultry processing wastewater," Bioresource Technology, no. 118, pp. 73-81, 2012.

[6] M. G. Hajaya and S. G. Pavlostathis, "Modeling the fate and effect of benzalkonium chlorides in a continuous-flow biological nitrogen removal system treating poultry processing wastewater," Bioresource Technology, no. 130, pp. 278-287, 2013.

[7] K. Yetilmezsoy and Z. Sapci-Zengin, "Recovery of ammonium nitrogen from the effluent of UASB treating poultry manure wastewater by MAP precipitation as a slow release fertilizer," Journal of Hazardous Materials, vol. 166, no. 1, pp. 260-269, 2009.

[8] E. V. Munch and K. Barr, "Controlled struvite crystallisation for removing phosphorus from anaerobic digester sidestreams," Water Research, vol. 35, no. 1, pp. 151-159, 2001.

[9] C. Guo, V. Stabnikov, S. Kuang, and V. Ivanov, “The removal of phosphate from wastewater using anoxic reduction of iron ore in the rotating reactor," Biochemical Engineering Journal, vol. 46, no. 2, pp. 223-226, 2009. 
[10] W. Guan, F. Y. Ji, Q. K. chen, P. Yan, and L. Pei, "Synthesis and enhanced phosphate recovery property of porous calcium silicate hydrate using polyethyleneglycol as pore-generation agent," Materials, vol. 6, no. 7, pp. 2846-2861, 2013.

[11] W. Guan, F. Y. Ji, Q. K. Chen, P. Yan, and Q. Zhang, "Preparation and phosphorus recovery performance of porous calciumsilicate-hydrate," Ceramics International, vol. 39, no. 2, pp. 13851391, 2013.

[12] W. Guan, F. Y. Ji, D. X. Fang et al., "Porosity formation and enhanced solubility of calcium silicate hydrate in hydrothermal synthesis," Ceramics International, vol. 40, no. 1, pp. 1667-1675, 2014.

[13] W. Guan, F. Y. Ji, Q. K. Chen, P. Yan, and W. W. Zhou, "Influence of hydrothermal temperature on phosphorus recovery efficiency of porous calcium silicate hydrate," Journal of Nanomaterials, vol. 2013, Article ID 451984, 6 pages, 2013.

[14] Y.-H. Song, D. Donnert, U. Berg, P. G. Weidler, and R. Nueesch, "Seed selections for crystallization of calcium phosphate for phosphorus recovery," Journal of Environmental Sciences, vol. 19, no. 5, pp. 591-595, 2007.

[15] W. Guan, F. Y. Ji, Y. Cheng et al., "A novel synthesis method of porous calcium silicate hydrate based on the calcium oxide/polyethylene glycol composites," Journal of Nanomaterials, vol. 2013, Article ID 542109, 7 pages, 2013.

[16] M. Özen, M. Mertens, J. Luyten, F. Snijkers, H. D’Hondt, and P. Cool, "Hydrothermal synthesis of carbonate-free submicronsized barium titanate from an amorphous precursor: synthesis and characterization," Ceramics International, vol. 38, no. 1, pp. 619-625, 2012.

[17] W. Cai, B. G. Zhang, Y. X. Jin et al., "Behavior of total phosphorus removal in an intelligent controlled sequencing batch biofilm reactor for municipal wastewater treatment," Bioresource Technology, vol. 132, pp. 190-196, 2013.

[18] D. Seyhan, "Country-scale phosphorus balancing as a base for resources conservation," Resources, Conservation and Recycling, vol. 53, no. 12, pp. 698-709, 2009.

[19] E.-H. Kim, S.-B. Yim, H.-C. Jung, and E.-J. Lee, "Hydroxyapatite crystallization from a highly concentrated phosphate solution using powdered converter slag as a seed material," Journal of Hazardous Materials, vol. 136, no. 3, pp. 690-697, 2006.

[20] K. Suzuki, Y. Tanaka, K. Kuroda et al., "Removal and recovery of phosphorous from swine wastewater by demonstration crystallization reactor and struvite accumulation device," Bioresource Technology, vol. 98, no. 8, pp. 1573-1578, 2007.

[21] F. Dong, Y. J. Sun, M. Fu, Z. B. Wu, and S. C. Lee, "Room temperature synthesis and highly enhanced visible light photocatalytic activity of porous $\mathrm{BiOI} / \mathrm{BiOCl}$ composites nanoplates microflowers," Journal of Hazardous Materials, vol. 219-220, pp. 26-34, 2012.

[22] F. Dong, Y. J. Sun, M. Fu, W. K. Ho, S. C. Lee, and Z. B. Wu, "Novel in situ n-doped $(\mathrm{BiO})_{2} \mathrm{CO}_{3}$ hierarchical microspheres self-assembled by nnosheets as efficient and durable visible light driven photocatalyst," Langmuir, vol. 28, no. 1, pp. 766-773, 2012.

[23] N. Demirkiran and A. Künkül, "Dissolution kinetics of ulexite in perchloric acid solutions," International Journal of Mineral Processing, vol. 83, no. 1-2, pp. 76-80, 2007.

[24] Y. Liu, X. Sheng, Y. H. Dong, and Y. J. Ma, "Removal of highconcentration phosphate by calcite: effect of sulfate and $\mathrm{pH}$," Desalination, vol. 289, pp. 66-71, 2012. 

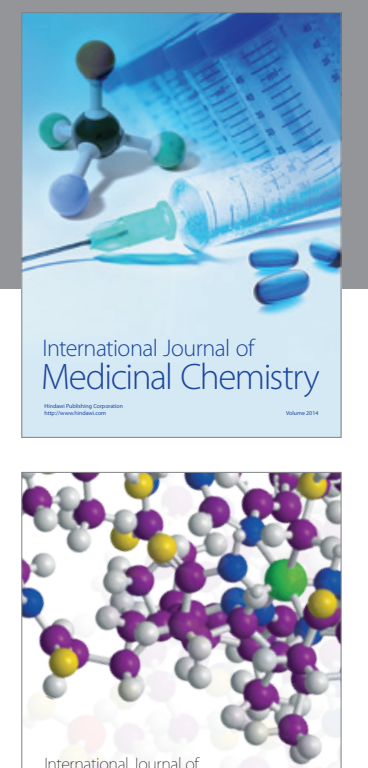

\section{Carbohydrate} Chemistry

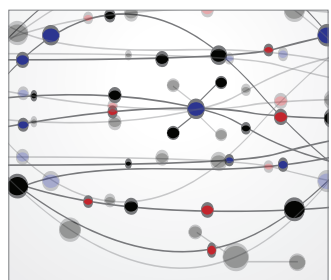

The Scientific World Journal
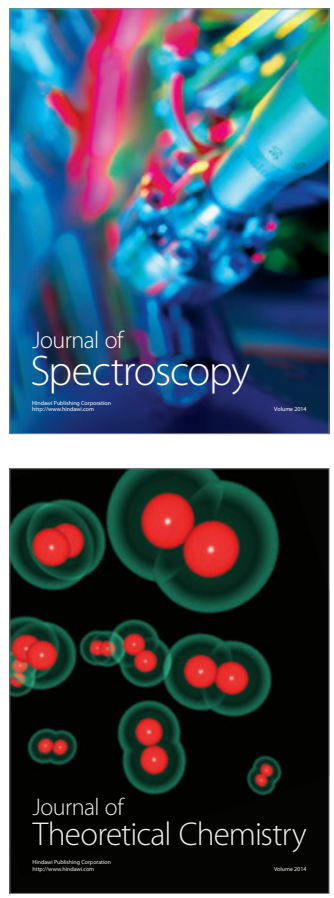
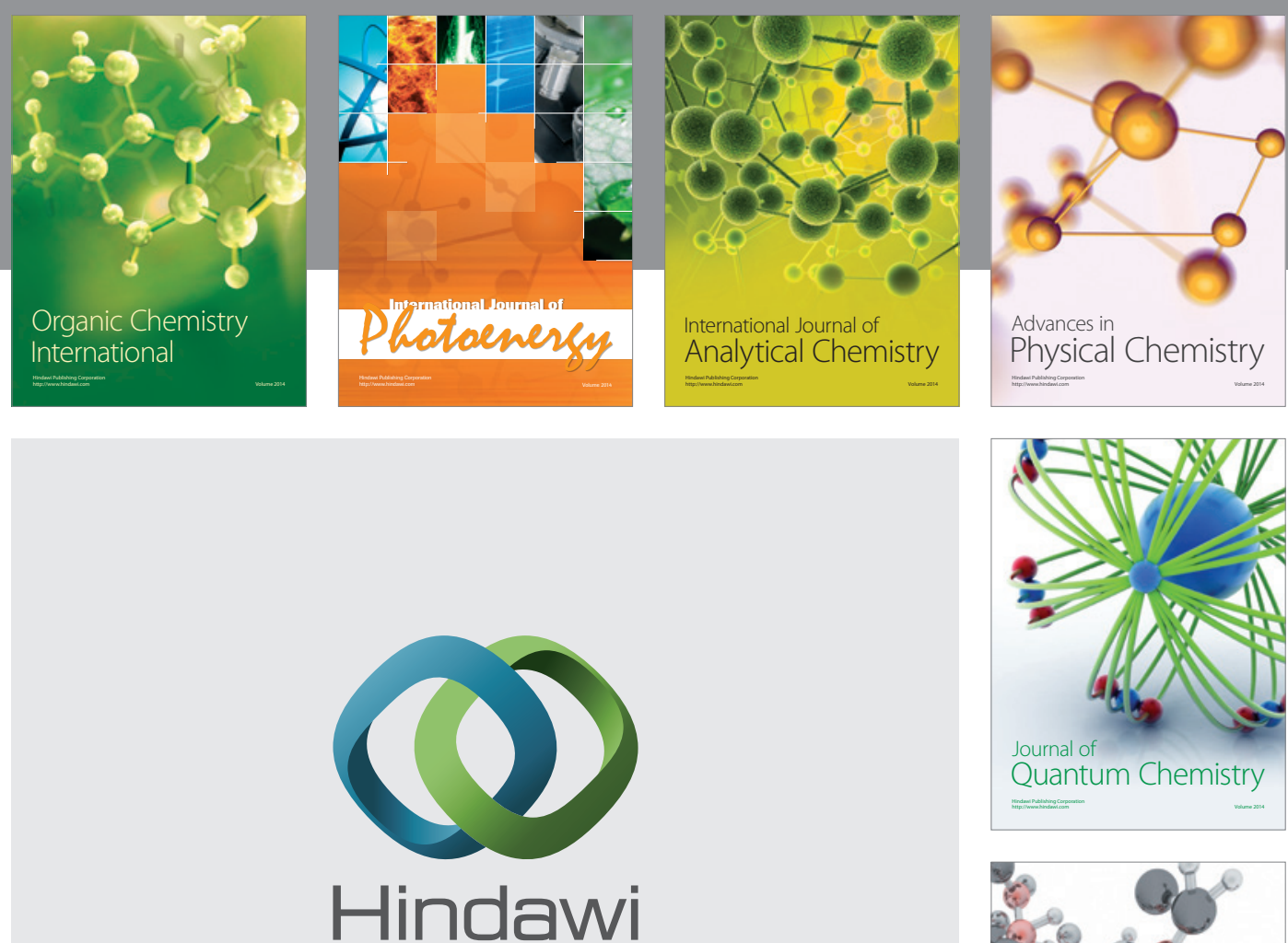

Submit your manuscripts at

http://www.hindawi.com

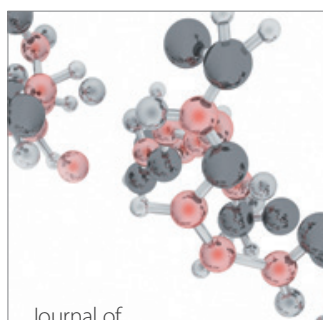

Analytical Methods

in Chemistry

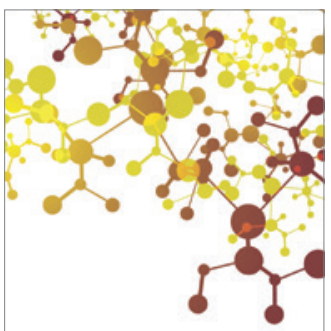

Journal of

Applied Chemistry

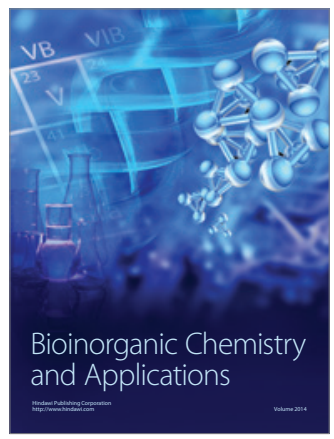

Inorganic Chemistry
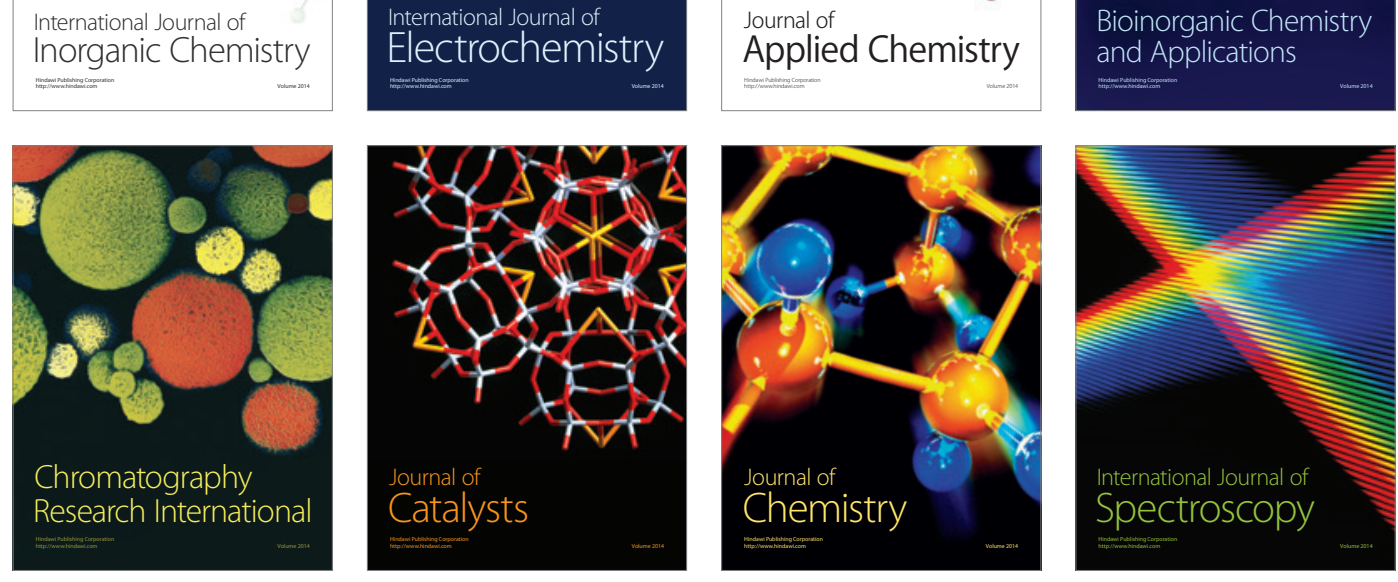